\title{
RÉGIMEN JURÍDICO DE LA PRODUCCIÓN ECOLÓGICA EN ESPAÑA. REUS Y AEDA. 2021
}

\author{
IsaAC De La Villa Briongos
}

La obra que el lector tiene en sus manos, publicada en 2021 por la editorial REUS y la Asociación española de Derecho agrario, desarrolla el régimen jurídico de la producción ecológica en España, teniendo como principal objetivo el de acercar el régimen jurídico de este tipo de producción a todos aquellos profesionales del sector o no, que deseen conocer de un modo accesible y didáctico el panorama regulador tanto a nivel nacional como a nivel de derecho comunitario de esta figura de calidad, así como también, los diferentes problemas a los que deben enfrentarse sus posibilidades de futuro y, por supuesto, el régimen jurídico de su protección.

Para desarrollar este objetivo, la monografía se ha sido estructurado en dos partes: la primera de ellas, desarrolla la regulación sui generis a través del estudio de las normativas internacionales, comunitarias y también nacionales específicas de la producción ecológica en la cual examinan todas las novedades incluidas las establecidas en el nuevo Reglamento (UE) 2018/848 del Parlamento Europeo y del Consejo, de 30 de mayo de 2018, sobre producción ecológica y etiquetado de los productos ecológicos y por el que se deroga el Reglamento (CE) n ${ }^{\circ} 834 / 2007$ del Consejo.

Y la segunda parte queda centrada en el estudio y análisis de la problemática a la que debe enfrentarse la producción ecológica dentro de la cual destaca la influencia del precio (mayor en los productos ecológicos que los convencionales) los conflictos derivados de la contaminación cruzada de cultivo, junto con el fraude alimentario relacionado con la misma además se realizarán las posibles las posibilidades de desarrollo de este tipo de producción mediante el estudio de la multifuncionalidad.

Finalmente se acometerá el régimen jurídico de la protección de esta figura frente a la amenaza a la que se ve sometida tanto desde el punto de vista de los consumidores y sus posibilidades de defensa frente al fraude alimentario, así como también desde el punto de vista de los propios productores y las prácticas desleales que pueden suponer un problema para el desarrollo de esta actividad.

Por lo expuesto, la obra la consideramos de referencia tanto para las investigaciones referidas al estudio normativo como en lo referente a las cuestiones prácticas cuando desarrolla el comercio con respecto a terceros países, la coexistencia entre sistemas productivos, el etiquetado, en sus diferentes escenarios. Queriendo trasladar al lector la claridad expositiva del autor en el análisis del régimen jurídico internacional, comunitario y nacional y en su capacidad de respuesta a las cuestiones que plantea, así como el análisis de nuevos retos.

María José Cazorla González

Profesora Titular de Derecho civil

Universidad de Almería 